\title{
The Effects of Curcumin against the Inflammatory Response in Patients with Acute Coronary Syndrome
}

Idrus Alwi $^{1 *}$, Teguh Santoso ${ }^{1}$, Slamet Suyono², Bambang Sutrisna ${ }^{3}$, Frans D Suyatna ${ }^{4}$, Siti Boedina Kresno ${ }^{5}$ and Erni Purwaningsih ${ }^{6}$

${ }^{1}$ Cardiology Division, Department of Internal Medicine, University of Indonesia, Cipto Mangunkusumo Hospital, Jakarta, Indonesia

${ }^{2}$ Metabolic Endocrine and Diabetes Division, Department of Internal Medicine, University of Indonesia, Cipto Mangunkusumo Hospital, Jakarta, Indonesia

${ }^{3}$ Department of Epidemiology, University of Indonesia, Jakarta, Indonesia

${ }^{4}$ Department of Pharmacology, University of Indonesia, Jakarta, Indonesia

${ }^{5}$ Department of Clinical Pathology, University of Indonesia, Cipto Mangunkusumo Hospital, Jakarta, Indonesia

${ }^{6}$ Department of Pharmacy, University of Indonesia, Jakarta, Indonesia

\begin{abstract}
Background: The human inflammatory response plays an important role in the pathogenesis of atherosclerosis. An increase in the inflammatory responses notable by the levels of highly sensitive C-Reactive Protein (hsCRP) may be able to predict future cardiovascular events and the prognosis of post-acute coronary syndrome (ACS). In animal experiments and human in-vitro experiments, curcumin has been proved to have anti-inflammatory effects. The effect of curcumin against the inflammatory response in ACS has not been identified. This study observes the effects of curcumin against the human inflammatory responses in patients with ACS.
\end{abstract}

Methods: This multicenter double-blinded placebo controlled randomized trial was located at the Intensive Coronary Care Unit (ICCU) of Cipto Mangunkusumo General Hospital, Persahabatan General Hospital and MMC Hospital in Jakarta, Indonesia. 75 ACS patients were randomized into four groups, with the three intervention group (group I-III) consisting of 15 patients and 30 patients in the placebo group (IV). The participants of this study was randomly allocated curcumin in three different doses, group I was provided $15 \mathrm{mg}$ t.i.d, group II was provided $30 \mathrm{mg}$ t.i.d., group III was provided $60 \mathrm{mg}$ t.i.d, and group IV was provided placebo.

Results: In this study, we discovered that group I experienced a significant decrease in the level of hsCRP compared to placebo during the first month $(p=0.04)$. Curcumin in low doses proved to be most effective in reducing the hsCRP levels, rather than moderate- or high doses. Moderate-dose curcumin was in second place, followed by high-dose curcumin

Conclusion: The use of low-dose curcumin in AC patients has significantly reduced the level of hsCRP after one week of use.

Keywords: Inflammatory response; hsCRP; Acute coronary syndrome; ACS; Curcumin

Abbreviations: ACS: Acute Coronary Syndrome; AMI: Acute Myocardial Infarct; ALT: Alanine aminotransferase; AST: Aspartate aminotransferase; BMI: Body Mass Index; BG: Blood Glucose; BP: Blood Pressure; CM: Centimeter; CCS: Canadian Cardiology Society; CHD: Chronic Heart Disease; CK: Creatine Kinase; CK-MB: Creatine Kinase-MB; DM: Diabetes Mellitus; ECG: Electrocardiogram; FBG: Fasting Blood Glucose; HbA1C: Hemoglobin A1C; HD: High Dose; HDL: High Density Lipoprotein; HPLC: High Performance Liquid Chromatography; hsCRP: High sensitivity C-reactive protein; ICCU: Intensive Cardiac-Care Unit; Kg: Kilogram; LD: Low Dose; LDL: Low Density Lipoprotein; M: Meter; MD: Mid Dose; Mg: Miligram; MMC: Metropolitan Medical Care; NS: Not Significant; NSAID: Nonsteroidal Anti-Inflammatory Drugs; NSTEMI: Non-ST Elevation Myocardial Infarct; PERKENI: Perkumpulan Endokrinologi Indonesia; SD: Standard Deviation; STEMI: ST-Elevation Myocardial Infarct; UAP: Unstable Angina Pectoris

\section{Introduction}

There is new evidence that indicates that atherosclerosis and all of its manifestations, such as Acute Coronary Syndrome (ACS), are in fact an inflammatory disease [1-4]. Increased levels of hsCRP (highly sensitive C-reactive Protein) were found in patients with unstable angina pectoris and acute myocardial infarction [5-7]. This means that hsCRP may be able to predict the disease's instability and must be of prognostic value independently $[8,9]$. Highly sensitive C-reactive protein maybe found in the heart, coupled with its complements during an acute myocardial infarction [10] and acute coronary syndrome [11]. It may also affect the onset pattern of Acute Myocardial Infarction (AMI) [12].

In stable and unstable angina pectoris [7] and AMI [13], increased levels of hsCRP is a risk factor for cardiac events and is a predictor of restenosis after stenting $[14,15]$. Other studies has demonstrated that hsCRP may activate the complements that plays a role in worsening the inflammatory process [16].

Efforts to reduce the inflammatory response has been attempted, such as using aspirin [17] or antihyperlipidemia drugs, the statins $[18,19]$. Although aspirin and statins are the standard treatment for patients with ACS and are able to reduce inflammation, but the

*Corresponding author: Dr. Idrus Alwi, Cardiology Division, Department of Internal Medicine, Cipto Mangunkusumo National Central Referral General Hospital, JI Diponegoro No. 71, Senen, Jakarta Pusat, Indonesia-10430, Tel: 0811827144; E-mail: Idrus_a@hotmail.com

Received June 02, 2016; Accepted June 13, 2016; Published June 17, 2016

Citation: Alwi I, Santoso T, Suyono S, Sutrisna B, Suyatna FD, et al. (2016) The Effects of Curcumin against the Inflammatory Response in Patients with Acute Coronary Syndrome. Cardiovasc Pharm Open Access 5: 185. doi:10.4172/23296607.1000185

Copyright: (c) 2016 Alwi I, et al. This is an open-access article distributed under the terms of the Creative Commons Attribution License, which permits unrestricted use, distribution, and reproduction in any medium, provided the original author and source are credited. 
morbidity and the mortality rates remain high in patients with ACS. This study aims to evaluate whether the use of additional adjunctive therapies is able to reduce the inflammation process further.

Curcumin as an extract of turmeric (Curcuma longa/Curcuma domestica) and temulawak (Curcuma xanthorrhizae), is widely used for inflammatory diseases, because of its anti-inflammatory activity [20-21]. These herbs are native Indonesian herbs, from the ginger family (Zingiberaceae), which are easily found and are widely used in traditional medicine [22].

Very few studies on the effects of curcumin against the inflammatory response have been completed. These studies were mostly animal experimental studies and human in-vitro studies [23-26]. This is the first study that evaluates the anti-inflammatory qualities of curcumin for patients with ACS.

\section{Methods \\ Design}

This study was a double blind placebo-controlled randomized trial, designed to evaluate the effects of curcumin against the hsCRP levels in patients with ACS using three different dosages (low dosage, medium dosage, and high dosage).

\section{Location and time of the study}

This study was conducted at the ICCU of Cipto Mangunkusumo National Central General Hospital, Faculty of Medicine, University of Indonesia, the ICCU of Persahabatan General Hospital, the ICCU of MMC Hospital, and the ICCU of Medistra Hospital. This study began in May 2005 and ended in May 2006.

\section{Study subjects}

This study involved patients with ACS that were hospitalized at the ICCU of Cipto Mangunkusumo National Central General Hospital. The follow-up process lasted up to 2 months after release. A small number of participants were the patients hospitalized at the ICCU of Persahabatan General Hospital, MMC Hospital and Medistra Hospital. The patients were educated by the investigators/assistant investigators and their informed consent was obtained. The study was approved by the Institutional Ethical Committee of the Faculty of Medicine, the University of Indonesia.

\section{Sample size calculation}

In this section, we discuss whether or not the addition of curcumin would affect the level of the inflammatory response (hsCRP) in ACS patients. To achieve this, we used the t-test analysis for the 2 paired groups to calculate the sample size, the formula used:

$$
\mathrm{n}=\left(\mathrm{SD}^{2}[\mathrm{z \alpha}+\mathrm{z} \beta]^{2}\right) / \mathrm{d}^{2}
$$

with the assumption that with the expected higher power of $90 \%$ (or $=0.1, z \beta=1.28$ ) the minimal sample required for this research was 15 patients for the intervention group ( $\mathrm{n}=15$ for UAP and $\mathrm{n}=11$ for AMI), the SD according to Abdel Mouttaleb et al. the hsCRP levels in $\mathrm{UAP}$ was $11.6 \mathrm{mg} / \mathrm{L}(\mathrm{SD}=18.8)$ and in AMI was $8.7 \mathrm{mg} / \mathrm{L}(\mathrm{SD}=9.2)$, $[27,28]$ and $\alpha=0.05$. While for the control group was 30 patients with an hsCRP level of $2.3 \mathrm{mg} / \mathrm{L}(\mathrm{SD}=3.6)$.

\section{Inclusion and exclusion criteria}

The inclusion criteria were: (1) Patients with ACS who were hospitalized at the ICCU of Cipto Mangunkusumo National Central General Hospital, the ICCU of Persahabatan Hospital, MMC Hospital and Medistra Hospital who meet the ACS criteria with an onset of less than 72 hours, (2) Willing and able to provide informed consent to participate in this study.

The exclusion criteria were: (1) Have acute or chronic infections; (2) Have other concomitant diseases related to the inflammatory response, such as autoimmune diseases, connective tissue disorders, any type of malignancy, trauma or operations during the past month; (3) Is currently in corticosteroid, NSAID or immunosuppressant therapy; (4) Is currently prescribed statins as the treatment for CHD; (5) For the ACS group, statins are prescribed only after a blood sample was taken to evaluate the inflammatory response (before the intervention, for an observational study); (5) Is currently prescribed tiazolidindione; (6) Have chronic liver or kidney disease.

\section{Parameters/Documented variables}

The anamnesis of the patients obtained information on the age, gender, education level, ethnicity, history previous chest pain and myocardium infarction, smoking habits, history of medication or treatments, familial history of hypertension, and DM. While the physical examination measured the patient's blood pressure, height, weight, waist circumference, and the patient's heart measurements.

The clinical laboratory measurements taken included the peripheral blood counts: Hemoglobin, hematocrit, leukocytes, platelets; Levels of fasting blood glucose and postprandial blood glucose, $\mathrm{HbA1C}$, total cholesterol, direct LDL cholesterol, HDL cholesterol, and triglycerides. The inflammatory response is quantified using the hsCRP levels.

\section{Definition of variables}

Acute coronary syndrome (ACS) [6,7] includes a wide spectrum of cardiac emergency, such as ST-Elevation Myocardial Infarction (STEMI), Non ST-Elevation Myocardial Infarction (NSTEMI), unstable angina pectoris (UAP). Unstable angina pectoris [8] is defined as: 1) Prolonged angina occurring at rest, usually longer than 20 minutes; 2) New onset angina of at least the Canadian Cardiovascular Society Grading Scale (or CCS classification system) classification severity III; 3) A recent acceleration in angina that is accentuated by an increase in severity of at least 1 CCS class, to at least CCS class III.

The Canadian Classification of Angina [9] consists of four grades, they are Class I: Angina only during strenuous or prolonged physical activity; Class II: Slight limitation, with angina only during vigorous physical activity, such as climbing more than 1 flight of stairs; Class III: Symptoms with everyday living activities, such as climbing less than 1 flight of stairs; and Class IV: Inability to perform any activity without angina or angina at rest, i.e., severe limitation.

Acute myocardial infarction is defined as a typical increase of a gradual decrease of troponin levels or an increase of a rapid decrease of myocardium necrosis biochemical markers should be accompanied by at least one of the following:

a. Emergence of the symptoms of ischemia;

b. The development of pathological Q waves on the ECG;

c. ECG changes indicative of ischemia (ST segment elevation or depression);

d. Coronary Arterial Intervention (for example, coronary angioplasty).

Type 2 Diabetes Mellitus (DM) is defined using the diagnostic criteria for type $2 \mathrm{DM}$ (The Indonesian Consensus on Type $2 \mathrm{DM}$ Management, PERKENI 2002): [11] 
1. Random glucose level (venous plasma) $>200 \mathrm{mg} / \mathrm{dL}$; or

2. Fasting blood glucose level (venous plasma) $>126 \mathrm{mg} / \mathrm{dL}$ or;

3. Post-prandial plasma glucose level $>200 \mathrm{mg} / \mathrm{dl}$ after 2 hours of 75 gram glucose load during oral glucose tolerance test.

The patient's age is calculated based on the participant's Identity Card. If there was a six month difference from the date of birth the age would be rounded: if the patients are more than 6 months older than their birth date, his/her age would be rounded upwards; and if less than 6 months, it would be rounded downwards. The body weight was measured using the centigrade scale in kilograms $(\mathrm{kg})$ using the SECA digital 770 weighing scale. The body height was measured based on the centigrade scale in centimeters $(\mathrm{cm})$ using the Microtois CMS tool. The body mass index (BMI) in $\mathrm{kg} / \mathrm{m}^{2}$, was calculated by using the following formula: the patient's body weight $(\mathrm{kg})$ divided by his/her body height $(\mathrm{m})^{2}$. The patient's waist circumference was measured using the SECA 200 Measuring Tape. The patient's blood glucose was measured using the hexokinase method from Roche. GlycoHb was measured using the kit produced by Boehringer.

\section{Curcumin}

The curcumin extract was from the roots (rhizome) of the turmeric plant (Curcuma domestica), which was produced according to the standard processing procedure of pharmaceutical materials at Eisai Manufacturer in Cianjur. Analysis of aerobic bacteria, fungi, E. Coli, S. Aureus and Pseudomonas aeruginosa produced negative results. The analysis of the concentration of curcumin was done using the HPLC method, at the Laboratory of Great Central Research and Development of Post-Harvest Agriculture (Laboratorium Pengujian Balai Besar Penelitian dan Pengembangan Pasca Panen Pertanian), Bogor.

The dosage of curcumin used in this study was based on the phase I study by Cheng et al. [12], i.e., no side effects were found in patients with advanced stage cancer provided curcuma extract up to 8 grams, equal to $180 \mathrm{mg}$ curcumin for 4 months. That was the highest curcumin dose that has been used in human clinical trials. In this study, high dose curcumin of $180 \mathrm{mg} /$ day was administered in three divided dosages of $60 \mathrm{mg} / \mathrm{dose}$, since the half-life of curcumin in blood plasma was 8-12 hours. The medium dosage was half of the high dosage, i.e., $90 \mathrm{mg} /$ day or $30 \mathrm{mg} /$ dose t.i.d; while the low-dose curcumin was a quarter of the high-dose, i.e., $45 \mathrm{mg} /$ day or $15 \mathrm{mg} /$ dose t.i.d.

The length of the curcumin therapy was 2 months, based on a study by Ramirez-Bosca et al. [13], which demonstrated that curcuma extract would significantly reduce the levels of lipid peroxides in 2 months.

\section{Data collection}

In the routine blood test and blood chemistry tests, samples of the peripheral venous blood were taken after a fasting period (10-12 hours), and then another sample was take 2 hours post-prandial and sent to the Clinical Laboratory using the standard procedures. For the IL-6 level, the blood samples were taken from the vein in accordance to the standard procedure and sent to the Clinical Laboratory. Consecutive sampling of patients with ACS was performed in patients who were hospitalized at ICCU of Cipto Mangunkusumo National Central General Hospital, Persahabatan General Hospital, MMC and Medistra Hospital between May 2005 and May 2006.

\section{Randomization}

The effects of curcumin was compared with the hsCRP level. The curcumin groups were divided into 3 sub-groups: Group I or the lowdose group received $3 \times 15 \mathrm{mg}$ curcumin; Group II or the moderate- dose group received $3 \times 30 \mathrm{mg}$ curcumin; and Group III or the high-dose group received $3 \times 60 \mathrm{mg}$ curcumin. The randomization was achieved using the computerized block-random method, with each intervention group consisting of 15 patients and 30 patients in the placebo group.

\section{Processing technique and data analysis}

All of the data collected continuously was coded and tabulated using STATA, and then its statistics were calculated. A parametric test was performed on variables with normal distribution; while variables with abnormal distribution were transformed so that the parametric test can be performed. All of the calculation used the significance level of $\mathrm{p}<0.05$, which was calculated by using the STATA program. In order to demonstrate the evidence for the effect of curcumin against hsCRP in patients with ACS, paired T-test was performed.

\section{Results}

\section{Subject characteristics}

From Table 1, we discovered that there were no significant differences on age, sex, DM, smoking, hypertension, body height, body weight, BMI, waist circumference, BP systolic, and BP diastolic among the four groups. This indicates that the randomization has been performed quite well.

From the Table 2, we discovered that there were no significant differences on laboratory parameters such as total cholesterol, LDL cholesterol, HDL cholesterol and triglycerides level, fasting blood glucose, 2-hours PP blood glucose, glyco $\mathrm{Hb}$, triglycerides, $\mathrm{Hb}, \mathrm{Ht}$, leukocytes, platelets, ureum, creatinine, AST, and ALT among the four groups. There was no significant difference of the ACS type and location among the four groups. There was no significant difference of statin drug (simvastatin), aspirin, ACE inhibitor and the DM drugs among the four groups. None of patient had used tiazolidindione. There was no significant difference of compliance percentage among the four groups.

\section{The effects of curcumin against hsC-reactive protein level}

In Table 3 we can see that compared to placebo, the delta decrease between the first week and the first month in the low-dose curcumin

\begin{tabular}{|c|c|c|c|c|c|c|c|c|}
\hline \multirow[t]{2}{*}{ Variables } & \multicolumn{2}{|c|}{$\begin{array}{l}\text { Placebo } \\
n=26(\%)\end{array}$} & \multicolumn{2}{|c|}{$\begin{array}{c}\text { Curcumin LD } \\
n=15(\%)\end{array}$} & \multicolumn{2}{|c|}{$\begin{array}{c}\text { Curcumin } \\
\text { MD } \\
n=14(\%)\end{array}$} & \multicolumn{2}{|c|}{$\begin{array}{c}\text { Curcumin HD } \\
n=15(\%)\end{array}$} \\
\hline & Mean & SD & Mean & SD & Mean & SD & Mean & SD \\
\hline Age, year & 54.31 & 8.55 & 58.6 & 13.73 & 54.29 & 9.47 & 54.47 & 8.70 \\
\hline Male & \multicolumn{2}{|c|}{23} & \multicolumn{2}{|c|}{10} & \multicolumn{2}{|c|}{11} & \multicolumn{2}{|c|}{12} \\
\hline Female & \multicolumn{2}{|l|}{3} & \multicolumn{2}{|c|}{5} & \multicolumn{2}{|l|}{3} & \multicolumn{2}{|l|}{3} \\
\hline DM & \multicolumn{2}{|c|}{$7(26.92)$} & \multicolumn{2}{|c|}{$6(40)$} & \multicolumn{2}{|c|}{$5(35.71)$} & \multicolumn{2}{|c|}{$6(40)$} \\
\hline Smoking & \multicolumn{2}{|c|}{$15(57.69)$} & \multicolumn{2}{|c|}{$6(40)$} & \multicolumn{2}{|c|}{$5(35.71)$} & \multicolumn{2}{|c|}{$6(40)$} \\
\hline Hypertension & \multicolumn{2}{|c|}{$17(65.38)$} & \multicolumn{2}{|c|}{5 (33.3) } & \multicolumn{2}{|c|}{$4(28.57)$} & \multicolumn{2}{|c|}{$6(40)$} \\
\hline \multicolumn{9}{|c|}{ Physical Examination } \\
\hline Height (cm) & 161.73 & 7.45 & 159.19 & 11.33 & 159.74 & 6.90 & 159.57 & 8.18 \\
\hline Weight (kg) & 67.78 & 12.62 & 63.87 & 12.68 & 64.43 & 10.88 & 63.99 & 12.46 \\
\hline BMI $\left(\mathbf{k g} / \mathbf{c m}^{2}\right)$ & 25.81 & 3.89 & 25.06 & 3.19 & 25.12 & 2.82 & 25.05 & 3.68 \\
\hline $\begin{array}{c}\text { Waist } \\
\text { Circumference } \\
(\mathrm{cm})\end{array}$ & 89.97 & 12.40 & 86.66 & 9.14 & 87.96 & 9.60 & 86.40 & 9.86 \\
\hline $\begin{array}{l}\text { BP systolic, } \\
\text { mmHg }\end{array}$ & 124.15 & 20.43 & 118.4 & 27.27 & 117.93 & 19.82 & 122.67 & 15.90 \\
\hline $\begin{array}{l}\text { BP diastolic, } \\
\mathrm{mmHg}\end{array}$ & 75.23 & 14.11 & 71.00 & 16.92 & 71.29 & 14.50 & 73.67 & 10.18 \\
\hline
\end{tabular}

Table 1: Demographical and physical characteristics of the low-dose (LD) curcumin group, moderate-dose (MD) curcumin group, and high-dose (HD) curcumin group and the placebo group. 


\begin{tabular}{|c|c|c|c|c|c|c|c|c|}
\hline \multirow[t]{2}{*}{ Variables } & \multicolumn{2}{|c|}{$\begin{array}{c}\text { Placebo } \\
n=26\end{array}$} & \multicolumn{2}{|c|}{$\underset{n=15}{\text { Curcumin LD }}$} & \multicolumn{2}{|c|}{$\underset{n=14}{\text { Curcumin }}$ MD } & \multicolumn{2}{|c|}{$\underset{n=15}{\text { Curcumin HD }}$} \\
\hline & Mean & SD & Mean & SD & Mean & SD & Mean & SD \\
\hline \multicolumn{9}{|c|}{ Laboratory Parameters } \\
\hline Total cholest, mg/dL & 207.23 & 58.23 & 202.67 & 59.64 & 211.71 & 55.18 & 190.87 & 36.17 \\
\hline LDL cholest, mg/dL & 148.73 & 49.36 & 139.07 & 55.07 & 149.5 & 40.84 & 133.87 & 33.49 \\
\hline HDL cholest, mg/dL & 38.04 & 8.80 & 42.13 & 10.44 & 40.50 & 9.15 & 41.13 & 8.82 \\
\hline Triglycerides, mg/dL & 146.15 & 63.18 & 151.53 & 91.37 & 145.64 & 47.99 & 119.40 & 34.08 \\
\hline FBG, mg/dL & 130.58 & 69.13 & 118.27 & 37.80 & 123.50 & 43.34 & 114.87 & 23.94 \\
\hline 2-hours PP BG, mg/dL & 148.85 & 61.81 & 155.73 & 61.45 & 176.79 & 108.79 & 156.27 & 53.95 \\
\hline Glyco Hb, \% & 6.75 & 1.60 & 7.31 & 1.98 & 7.25 & 1.93 & 7.17 & 1.72 \\
\hline $\mathrm{Hb}, \mathrm{g} / \mathrm{dL}$ & 14.06 & 1.75 & 13.65 & 1.66 & 14.41 & 2.57 & 12.97 & 2.24 \\
\hline $\mathrm{Ht}, \%$ & 40.67 & 5.59 & 39.70 & 4.92 & 41.99 & 7.60 & 38.00 & 6.29 \\
\hline Leuko, cell/mL & 13.23 & 4.95 & 12.17 & 4.62 & 12.46 & 4.82 & 12.09 & 3.53 \\
\hline Platelet, thousand cells $/ \mathrm{mL}$ & 271.77 & 66.61 & 258.8 & 81.42 & 276.64 & 71.07 & 256.87 & 50.43 \\
\hline
\end{tabular}

Table 2: Laboratory characteristics of the low-dose (LD) curcumin group, moderate-dose (MD) curcumin group, and high-dose (HD) curcumin group and the placebo.

\begin{tabular}{|c|c|c|c|c|c|c|c|c|c|c|c|c|c|c|}
\hline \multirow{3}{*}{ Variables } & \multicolumn{8}{|c|}{ Log: Mean of hsCRP Level } & \multicolumn{3}{|c|}{$\begin{array}{c}\text { Mean Percentage of Changes After } \\
\text { Intervention }\end{array}$} & \multicolumn{2}{|c|}{$\begin{array}{c}\text { Delta Percentage of } \\
\text { Decrease }\end{array}$} & \multirow{3}{*}{$\mathbf{p}$} \\
\hline & \multicolumn{2}{|c|}{$\begin{array}{c}\text { Before } \\
\text { Intervention }\end{array}$} & \multicolumn{2}{|c|}{ 1-Week } & \multicolumn{2}{|c|}{ 1-Month } & \multicolumn{2}{|c|}{ 2-Month } & \multirow{2}{*}{$\begin{array}{c}\text { 1-Week } \\
\text { vs. } \\
\text { Before }\end{array}$} & \multirow{2}{*}{$\begin{array}{c}\text { 1-Month } \\
\text { vs } \\
1-\text { Week }\end{array}$} & \multirow{2}{*}{$\begin{array}{l}\text { 2-Month vs } \\
\text { 1-Month }\end{array}$} & \multirow{2}{*}{$\begin{array}{c}\text { 1-Week } \\
\text { vs. } \\
\text { 1-Month }\end{array}$} & \multirow{2}{*}{$\begin{array}{l}\text { 1-Month } \\
\text { vs. } \\
\text { 2-Month }\end{array}$} & \\
\hline & Mean & SD & Mean & SD & Mean & SD & Mean & SD & & & & & & \\
\hline $\begin{array}{l}\text { Curcumin } \\
\text { LD (n) }\end{array}$ & 3.90 & 1.25 & 2.66 & 1.10 & 1.22 & 0.77 & 0.96 & 1.16 & -38.10 & -78.60 & -82.50 & -40.50 & -38.80 & 0.04 \\
\hline $\begin{array}{l}\text { Curcumin } \\
\text { MD (n) }\end{array}$ & 3.78 & 1.78 & 2.29 & 1.46 & 1.48 & 1.12 & 1.27 & 1.30 & -68.70 & -78.70 & -76.20 & -9.90 & -8.50 & NS \\
\hline $\begin{array}{l}\text { Curcumin } \\
\text { HD (n) }\end{array}$ & 3.66 & 1.36 & 2.27 & 1.55 & 0.85 & 0.90 & 1.02 & 1.02 & -59.10 & -62.60 & +20 & -23.40 & +10.80 & NS \\
\hline $\begin{array}{l}\text { Placebo } \\
\text { Group (n) }\end{array}$ & 4.26 & 0.95 & 2.62 & 1.08 & 1.36 & 1.20 & 1.01 & 1.01 & -71 & -85.30 & -74.50 & -16.30 & -34.50 & NS \\
\hline
\end{tabular}

Table 3: Log: Mean of HSCRP level in patients with ACS before and after 1-week, 1-month, 2-month intervention and the percentage mean of its changes and the percentage delta of its decrease according to the curcumin dose.

group was significantly higher compared to the placebo group $(40.5 \%$ versus $16.3 \%, \mathrm{p}=0.04$; Table 3 ). The delta decrease between the first month and the second month in the low-dose curcumin group was higher vs. placebo group (38.80\% vs. $34.50 \%, \mathrm{p}=0.48)$, but it was not statistically significant.

The delta decrease between the first week and the first month in the moderate-dose curcumin group was lower than in the placebo group (9.90\% versus $16.3 \%, p=0.88$ ). The delta decrease between the first month and the second month in the moderate-dose curcumin group was lower vs. placebo group, but it was not statistically significant (8.50\% versus $34.50 \%$, $\mathrm{p}=0.66)$.

The delta decrease between the first week and the first month in the high-dose curcumin group was higher compared to the placebo group (23.40\% versus $16.3 \%, p=0.26)$. The delta decrease between the first month and the second month in the high-dose curcumin group was higher vs. placebo group, but it was not statistically significant $(10.80 \%$ versus $34.50 \%, \mathrm{p}=0.88$ )

\section{Discussion}

Curcuma longa Linn and Curcuma xanthorriza has long been known as coloring and flavoring substance in daily Indian and Indonesian cuisine. This study is the first study reporting the effect of curcumin against hsCRP level in patients with acute coronary syndrome.

\section{The effect of curcumin against hsCRP level}

There have been little reports about the effect of curcumin against inflammatory response. The studies are still limited on experimental studies and in-vitro for human. According to Abe et al. [23], in a study comprising of 15 healthy subjects, curcumin has an inhibitory effect against the production of interleukin-8 (IL-8), monocyte chemotactic protein-1 (MCP-1), interleukin-1 $\beta$ (IL-1 $\beta$ ) and TNF- $\alpha$ in peripheral blood monocytes and alveolar macrophages; however, what mechanism used is unknown. Other investigator also reported that curcumin inhibits the action of IL-12 in the macrophages in animal models $[24,25]$ Acccording to Jobin et al. [26], in an experimental animal study, curcumin inhibits activated cytokines by utilizing nuclear factor $\kappa-\mathrm{B}(\mathrm{NF}-\kappa \mathrm{B})$ and inhibits the expression of proinflammatory genes by inhibiting the signal on I- $\kappa \mathrm{B}$ kinase activity.

Our study indicated that in the first week after intervention, there was decreased hsCRP level in the low-dose curcumin $(38.10 \%$ decreases), moderate-dose curcumin (68.70\% decreases), high-dose curcumin $(59.10 \%$ decrease) or the placebo group (71\% decreases). Such decrease was not significantly different compared to the placebo. The study demonstrated that the kinetics of hsCRP level reached the peak level after 48-72 hours, which will decrease afterward. The decrease in the placebo group after 1 week reached $71 \%$.

During the first month, the hsCRP level demonstrated further decrease. In the low-dose curcumin group, the hsCRP level decreased 78.60\%; while in the moderate-dose curcumin group the hsCRP level decreased $78.70 \%$; and the high dose hsCRP level decreased $62.60 \%$ compared to the placebo decreased $85.30 \%$. There was no significant differences in the decreased hsCRP level between the three groups compared to placebo. However, there a sharp decrease in the percentage of delta decrease between the first week to the first month in the low-dose curcumin group compared to the placebo ( $\mathrm{p}=0.04$; Table 3 ). From this fact, we can conclude that lowdose curcumin has anti-inflammatory effect, but the effect is only obvious after one month intervention. In the first week, the effect has not emerged 
Citation: Alwi I, Santoso T, Suyono S, Sutrisna B, Suyatna FD, et al. (2016) The Effects of Curcumin against the Inflammatory Response in Patients with Acute Coronary Syndrome. Cardiovasc Pharm Open Access 5: 185. doi:10.4172/2329-6607.1000185

Page 5 of 6

because the hsCRP level is still being affected by acute phase response due to injury in ACS.

In the second month, the curcumin level experienced a steeper decrease. In the low-dose, moderate-dose, high-dose curcumin group, the hsCRP level decreased $82.50 \%, 76.20 \%$, and increased $20 \%$, respectively, compared to the placebo group which reached $75.50 \%$. However, there was no statistical significance. Regarding the percentage of delta decrease between the first and second month, there was a slope decrease in low-dose curcumin group compared to the placebo. Such slope decrease occurs because the acute phase response due to injury in ACS has begun to reduce; therefore, it is assume that the significant effect of curcumin on hsCRP level requires longer exposure (intervention).

\section{The side effects of curcumin}

There was no significant difference in the total number of side effects such as nausea, vomiting, or diarrhea experienced compared to the placebo. Although some studies showed that curcumin may cause nausea, vomiting or diarrhea, however the dosage used was higher than the dose applied in our study. No side effects were experienced during the titration process $(45 \mathrm{mg} /$ day, $90 \mathrm{mg} /$ day up to $180 \mathrm{mg} /$ day). Some patients demonstrated the improvement effect on their appetite.

Its effects against liver function (based on AST and ALT levels) in all four groups were not significantly different. Some studies indicated that curcumin may improve liver function by reducing the levels of AST and ALT. No patients experienced an improvement renal function, which was similar as in the placebo group.

We found no abnormal bleeding during hospitalization in patients who used thrombolitic agents, heparin or antiplatelets (aspirin, clopidogrel, aspirin and clopidogrel). Furthermore, there was also no effect found in the levels of the patients' Hemoglobin, leukocytes and platelets. Some experimental studies showed that curcumin reduced the platelet aggregation; therefore, caution should be exercised for prescribing antiplatelets and anticoagulants.

\section{Conclusion}

In this study, we discovered that low-dose and moderate-dose curcumin may be able to reduce the hsCRP levels after 1 month of use. This effect is clearer after the 2 month-intervention. The group with the largest decrease in the group prescribed the low-dose curcumin; while moderate-dose curcumin shows smaller decrease. In contrast, the high-dose curcumin demonstrated increased hsCRP levels. From this study we discovered that the low-dose curcumin in the first month has the highest delta decrease of hsCRP level.

\section{Funding}

Dr. Cipto Mangunkusumo National Central Referral General Hospital.

\section{References}

1. Ross R (1999) Atherosclerosis--an inflammatory disease. N Engl J Med 340: 115-126.

2. Tracy RP (1999) Inflammation markers and coronary heart disease. Curr Opin Lipidol 10: 435-441.

3. Koenig W (1999) Atherosclerosis involves more than just lipids:focus on inflammation. Eur Heart J 1: T19-T26.

4. Libby P, Ridker PM, Maseri A (2002) Inflammation and atherosclerosis. Circulation 105: 1135-1143

5. Liuzzo G, Biasucci LM, Gallimore JR, Caligiuri G, Buffon A, et al. (1999) Enhanced inflammatory response in patients with preinfarction unstable angina. J Am Coll Cardiol 34: 1696-1703.

6. Yamashita H, Shimada K, Seki E, Mokuno H, Daida H (2003) Concentrations of interleukins, interferon, and C-reactive protein in stable and unstable angina pectoris. Am J Cardiol 91: 133-136.

7. Haverkate F, Thompson SG, Pyke SD, Gallimore JR, Pepys MB (1997) Production of C-reactive protein and risk of coronary events in stable and unstable angina. European Concerted Action on Thrombosis and Disabilities Angina Pectoris Study Group. Lancet 349: 462-466.

8. Biasucci LM, Liuzzo G, Grillo RL, Caligiuri G, Rebuzzi AG, et al. (1999) Elevated levels of C-reactive protein at discharge in patients with unstable angina predict recurrent instability. Circulation 99: 855-860.

9. Ferreirós ER, Boissonnet CP, Pizarro R, Merletti PF, Corrado G, et al. (1999) Independent prognostic value of elevated $\mathrm{C}$-reactive protein in unstable angina Circulation 100: 1958-1963.

10. Lagrand WK, Niessen HW, Wolbink GJ, Jaspars LH, Visser CA, et al. (1997) C-reactive protein colocalizes with complement in human hearts during acute myocardial infarction. Circulation 95: 97-103.

11. Abdelmouttaleb I, Danchin N, llardo C, Aimone-Gastin I, Angioï M, et al. (1999) C-reactive protein and coronary artery disease:additional evidence of the implication of an inflammatory process in acute coronary syndrome. Am Heart J 137: 346-351.

12. Kosuge M, Kimura K, Ishikawa T, Endo T, Shigemasa T, et al. (2000) Relation between $\mathrm{C}$-reactice protein levels on admission and pattern of acute myocardial infarction onset. Am J Cardiol 86: 83-86.

13. Ridker PM, Rifai N, Pfeffer MA, Sacks FM, Moye LA, et al. (1998) Inflammation, pravastatin, and the risk of coronary events after myocardial infarction in patients with average cholesterol levels. Circulation 98: 839-844.

14. Versaci F, Gaspardone A, Tomai F, Ilkay E, Akbulut M, et al. (2000) Predictive value of $C$-reactive protein in patients with unstable angina pectoris undergoing coronary artery stent implantation. Am J Cardiol 85: 92-95.

15. Angioi M, Abdelmouttaleb I, Rodriguez RM, Aimone-Gastin I, Adjalla C, et al. (2001) Increased C-reactive protein levels in patients with in-stent restenosis and its implications. Am J Cardiol 87: 1189-1193.

16. Mold C, Gewurz H, Du Clos TW (1999) Regulation of complement activation by C-reactive protein. Immunopharmacology 42: 23-30.

17. Ridker PM, Cushman M, Stampfer MJ, Tracy RP, Hennekens CH (1997) Inflammation, aspirin, and the risk of cardiovascular disease in apparently healthy men. $\mathrm{N}$ Engl J Med 336: 973-979.

18. Sacks FM, Pfeffer MA, Moye LA, Rouleau JL, Rutherford JD, et al. (1996) The effect of pravastatin on coronary events after myocardial infarction in patients with average cholesterol levels. Cholesterol and Recurrent Events Trial investigators. N Engl J Med 335: 1001-1009.

19. Jialal I, Stein D, Balis D, Grundy SM, Adams-Huet B, et al. (2001) Effect of hydroxymethyl glutaryl coenzyme A reductase inhibitor therapy on high sensitive C-reactive protein levels. Circulation 103: 1933-1935.

20. Chattopadhyay I, Biswas K, Bandyopadhyay U, Banerjee RK (2004) Turmeric and curcumin:biological actions and medicinal applications. Curr Science 87: 44-53.

21. Miquel J, Bernd A, Sempere JM, Díaz-Alperi J, Ramírez A (2002) The curcuma antioxidants: pharmacological effects and prospects for future clinical use. A review. Arch Gerontol Geriatrics 34: 37-46.

22. Dalimartha S (2001) Atlas Plant Drugs Indonesia. Jakarta, Trubus Agriwidya 2

23. Abe $Y$, Hashimoto S, Horie T (1999) Curcumin inhibition of inflammatory cytokine production by human peripheral blood monocytes and alveolar macrophages. Pharmacol Res 39: 41-47.

24. Kang BY, Song YJ, Kim KM, Choe YK, Hwang SY, et al. (1999) Curcumin inhibits Th1 cytokine profile in CD4+ $\mathrm{T}$ cells by suppressing interleukin-12 production in macrophages. Br J Pharmacol 128: 380-384.

25. Kang BY, Chung SW, Chung W, Im S, Hwang SY, et al. (1999) Inhibition of interleukin-12 production in lipopolysaccharide-activated macrophages by curcumin. Eur J Pharmacol 384: 191-195.

26. Jobin C, Bradham CA, Russo MP, Juma B, Narula AS, et al. (1999) Curcumin blocks cytokine-mediated NF-kappa B activation and proinflammatory gene expression by inhibiting inhibitory factor I-kappa B kinase activity. J Immunol 163: 3474-3483.

27. Antman EM, Anbe DT, Armstrong PW, Bates ER, Green LA, et al. (2004) ACC/ AHA guidelines for the management of patients with ST-elevation myocardial 
Citation: Alwi I, Santoso T, Suyono S, Sutrisna B, Suyatna FD, et al. (2016) The Effects of Curcumin against the Inflammatory Response in Patients with Acute Coronary Syndrome. Cardiovasc Pharm Open Access 5: 185. doi:10.4172/2329-6607.1000185

Page 6 of 6

infarction a report of the American College of Cardiology/American Heart Association Task Force on Practice Guidelines (Committee to revise the 1999 guidelines for the management of patients with acute myocardial infarction). Circulation 110: 588-636.
28. Abdelmouttaleb I, Danchin N, Ilardo C, Aimone-Gastin I, Angioï M, et al. (1999) C-Reactive protein and coronary artery disease: additional evidence of the implication of an inflammatory process in acute coronary syndromes. Am Heart J 137: 346-351. 